\title{
A New Look at Public Services Inequality: The Consistency of Neighborhood Context and Citizens' Perception across Multiple Scales
}

\author{
Chunzhu Wei *, Pablo Cabrera Barona and Thomas Blaschke \\ Department of Geoinformatics_Z__GIS, University of Salzburg, Schillerstrasse 30, 5020 Salzburg, Austria; \\ pablo.cabrera-barona@stud.sbg.ac.at (P.C.-B.); thomas.blaschke@sbg.ac.at (T.B.) \\ * Correspondence: chunzhu.wei@stud.sbg.ac.at
}

Academic Editors: Maria Antonia Brovelli, Hussein M. Abdulmuttalib, Peter Mooney, Chris Pettit and Wolfgang Kainz

Received: 2 May 2017; Accepted: 29 June 2017; Published: 4 July 2017

\begin{abstract}
A challenge in regional inequality is to identify the relative influence of objective neighborhood context on subjective citizens' attitudes and experiences of place. This paper first presents six groups of hierarchal neighborhoods in optimizing public service inequality (PSI) indicators based on census blocks collected in Quito, Ecuador. Multilevel models were then applied to understand the relative influence of neighborhood-level PSI on citizens' perceptions of place, including individual-level perceptions of neighborhood social cohesion and neighborhood safety, and self-perceived health status. Our results show that the internal variability of the individual perceptions that is explained by neighborhood context is strongly influenced by the scale of neighborhood units. A spatial consistency between objective neighborhood context and subjective individual perception of place plays a crucial role in propagating mixed-methods approaches (qualitative-quantitative) and improves the spatial interpretation of public services inequality. Neighborhood context and citizens' perception of place should be integrated to investigate urban segregation, thereby providing insights into the underlying societal inequality phenomenon and quality of life.
\end{abstract}

Keywords: public services inequality; clustering algorithms; neighborhood; citizen perception; perceptions of neighborhood safety; perceptions of neighborhood social cohesion; self-perceive health status

\section{Introduction}

The diversity of individual socioeconomic characteristics related to urban segregation phenomena has brought about a paradigm shift from the individual-level analysis to novel multilevel place-based perspectives [1-3]. Urban segregation is commonly used to characterize the social inequalities within the territory of cities, and reflects the unequal appropriation of land, goods, and services by different social classes $[4,5]$. Place-based urban segregation analyses often refer to the spatial definitions of the neighborhood, to identify a form of segregation that 'sours population groups into various neighborhood contexts and shapes the living environment at the neighborhood level' [6,7].

Neighborhood often refers to the geographic boundaries defined by the Census Bureau or other administrative agencies [8] and dissects space into segments, technically speaking, into polygons. Most administrative units are not necessarily suited to delineate place, which is more of a social construct. For example, the U.S. Census Bureau defines census blocks as the smallest place-based units of census areas that contain a minimum of 250 housing units and a maximum of 550 housing units, with an average of 1000 individuals (U.S. Census Bureau, 2010). Nevertheless, with the advantages of facilitating data collection and analysis in a uniform manner over well-defined boundaries, 
census blocks are the most common proxies for neighborhood definition in health and demographic research [9]. Yet, some scholars have questioned the ability of census blocks to capture a real functional neighborhood, because the census blocks are not designed to capture the notion of neighborhood. Several studies have used other parameters, such as the zip code areas or the clustering of housing units [10,11], to identify neighborhood. Still, this "one-size fits all" approach may be too simplistic [12] and may limit the analysis of multidimensional social phenomena. The appropriate neighborhood definition should be specific to the epidemiological outcome of interest in a transferable and conducting way. To better understand functional neighborhood definitions, we review and discuss below a collection of approaches for defining the term 'neighborhood' in terms of a social inequality analysis. Social inequality in neighborhood analysis most commonly seeks to identify social groups who differentially occupy socioeconomic standing in society [13].

In fact, many previous studies have highlighted the need for a definition of neighborhoods in urban segregation analysis. For instance, the establishment of a framework that enables a characterization of public services inequality on a suitable neighborhood scale becomes an essential prerequisite for the implementation of public health policy [14]. Some studies also analyzed place effects on citizens' well-being through the construction of functional neighborhoods characterized by socially homogeneous areas $[3,15,16]$. Neighborhood definition for urban segregation and social equity research, however, is still in its theoretical infancy. There is still a need for well-developed "theories of the middle-range" that can systematically delineate the spatial unit combining different social, geopolitical, and other contextual characteristics. Therefore, this research proposes a framework to semi-automatically aggregate census blocks based on the combinations of multiple accessibility-related indicators. The results are called aggregated zoning units and they represent the multidimensional characteristics of public services inequality (PSI) in a neighborhood.

Many previous studies have defined PSI as a composite index of several accessibility-related indicators to different types of public service resources (e.g., access to clean water, electricity, education, healthcare) $[8,17]$, to further identify the spatial and social inequality with important implications for urban planning [18-20]. This kind of accessibility represents the multidimensional phenomena of accessing a variety of urban services and resources. For instance, neighborhood units with a specified distance to public infrastructure (e.g., public health facility, supermarket, and sidewalks) are closely related to a series of social health status issues [21,22] and physical activities [23-25]. Therefore, integrating several multidimensional accessibility-related indicators, based on their spatial correlations and spatial heterogeneities, becomes an increasingly important manner of identifying neighborhoods in urban segregation analyses [26,27]. The discrepancies between neighborhood context and citizens' perceptions of place are emphasized.

Although census blocks are homogenous areas in terms of population density, they may not be suitable for demonstrating the urban segregation in terms of socioeconomic conditions. Clustering methods, which are data exploration tools for dividing multidimensional indicators into clusters, are therefore useful and efficient for aggregating census blocks to create neighborhood units. For instance, the hierarchical classification [28-30], the k-nearest neighbor collaborative technique [31,32], the automatic zoning procedure [33,34], the minimum spanning tree [35,36], the fuzzy c-means clustering [37], Moran's I [38], and the ward's minimum variance method [39] have been used to examine neighborhood effects on measuring social capital, public health, mortality, deprivation, economic capability, and so on. Nevertheless, the empirical knowledge on neighborhood derivation remains quite limited, and different clustering procedures involving various principles could differ significantly depending on the modeling scale [1]. The uncertainty of the modeling scale refers to the well-known modifiable areal unit problem (MAUP) $[33,40,41]$, and there is no decisive way to define the most suitable scale of neighborhoods.

Ideally, neighborhood units should have a strong sense of social and place identity, and a strong identity that helps to enhance citizens' awareness and perception of place [42]. The concept of perception of place was proposed in behavioural geography analyses to measure the residential understanding 
and feeling about human place attachment and place meaning [43]. It describes human relationships with places, expressed in different dimensions of human life and personal experiences [44]. In cities, the perception of place reflects the symbolic meaning people ascribe to places [45,46]. This awareness and perception of place are determined by citizens' social activities [47,48]. In this sense, neighborhood context can also be interpreted by citizens' social behaviors and self-perception of place [49-51]. Previous research has also demonstrated significant associations between objective neighborhood and individuals' perceptions of health and quality of life [20,52-55]. This point of neighborhood identification thus provides a possibility to validate the meaning of a neighborhood; it also leads to the requirement of multilevel modeling to examine the feasibility of newly designed neighborhoods versus original census blocks for understanding citizens' attitudes and experiences of neighborhood identity $[47,55]$. Therefore, in this study, we aim to explore the uncertainty of MAUP in neighborhood interpretations by comparing the discrepancies between objective neighborhood context and subjective citizens' perceptions of place across multiple scales [56,57].

The objectives of this research are twofold. First, different clustering algorithms were proposed to aggregate census blocks into multiple neighborhood scales based on multidimensional characteristics of public services inequality. Second, the variability of spatial consistency between objective neighborhood context and subjective individual perception of place was explored across multiple neighborhood scales.

\section{Study Area}

Latin America can be considered as the region of the world with the highest inequality in terms of access to services and other socioeconomic variables [58]. The selected study area is the capital city of Quito, Ecuador (Figure 1). Quito has 4037 census blocks, averaging about 398 persons per block. These standard census blocks are recognized by administrative agencies and local decision-makers, and can easily be linked to census-based information. Thus, census blocks can be treated as convenient geographic designations on which to base neighborhood measures.

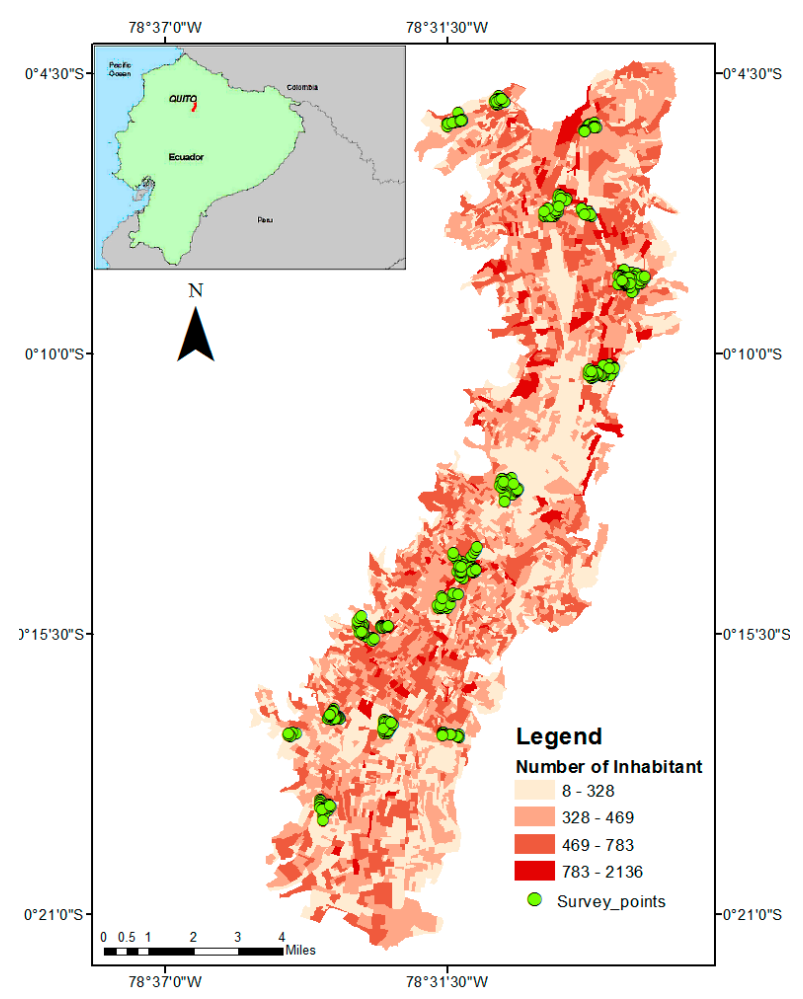

Figure 1. The study area, Quito, Ecuador. 


\section{Data Collection and Methodology}

This research is based on aggregated zones that were designed to maximize the external (between-area) variation of the PSI attribute while minimizing its internal (within-area) variation within each geographical unit. The workflow used in this study is fully illustrated in Figure 2 and summarized in the following paragraphs.

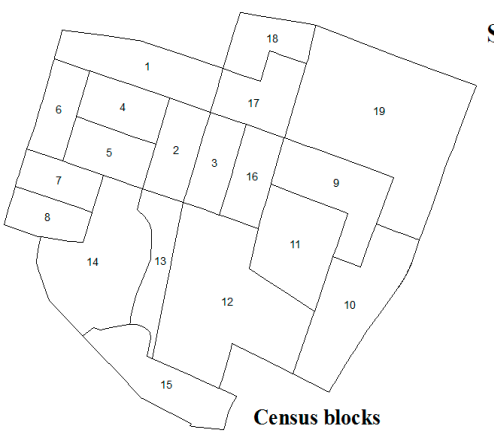

Step 1. Public service data pre-processing at the census block level

\begin{tabular}{l|l|l|l|l|l|l|l}
\hline & \multicolumn{7}{|c}{ Standardized values of } \\
\hline ID & NonDri & NonSew & NonEle & NonCol & Dist_H & Dist_E & Green \\
\hline 1 & 0.010 & 0 & 0 & 2.378 & 2.041 & 0.010 & 5.141 \\
\hline 2 & 0 & 0.009 & 0 & 6.193 & 0.531 & 0.009 & 0.491 \\
\hline 3 & 0 & 0 & 0 & 5.155 & 0.930 & 0 & 1.422 \\
\hline$\cdots$ & $\ldots$ & $\cdots$ & $\ldots$ & $\cdots$ & $\ldots$ & $\cdots$ & $\cdots$ \\
\hline 19 & 0 & 0 & 0.017 & 8.142 & 2.098 & 0 & 0.259 \\
\hline
\end{tabular}

Step 2. Classifying all census blocks into hierarchical categories of neighborhoods

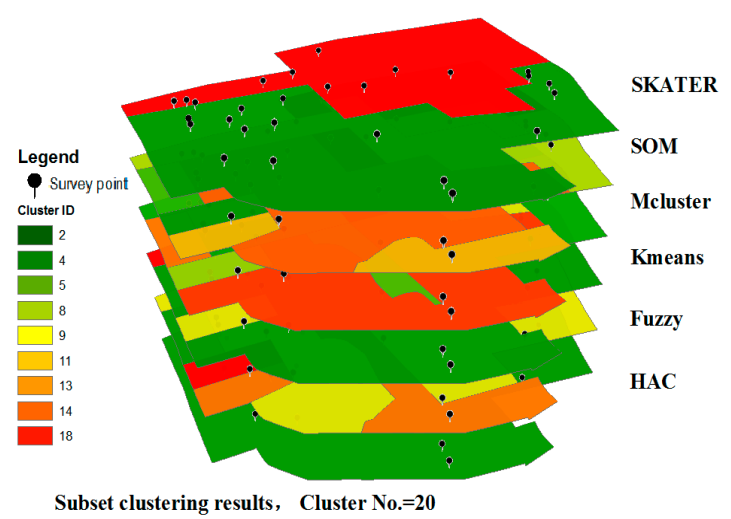
using six clustering methods

\begin{tabular}{l|c|c|c|c|c|c}
\multicolumn{7}{c}{ Neighborhood based on PSI values } \\
\hline & HAC & Kmeans & SKATER & SOM & Fuzzy & Mcluster \\
\hline Cluster No & Avg.PSI & Avg.PSI & Avg.PSI & Avg.PSI & Avg.PSI & Avg.PSI \\
\hline 3 & 0.386 & 0.389 & 0.566 & 0.416 & 0.566 & 0.415 \\
\hline 4 & 0.384 & 0.398 & 0.576 & 0.409 & 0.576 & 0.438 \\
\hline$\cdots$ & $\cdots$ & $\cdots$ & $\cdots$ & $\cdots$ & $\cdots$ & $\cdots$ \\
\hline 50 & 0.433 & 0.459 & 0.434 & 0.503 & 0.434 & 0.414 \\
\hline
\end{tabular}

Step 3. Multi-level modeling between residents' perceptions of neighborhood and

context information of cluster-defined neighborhood

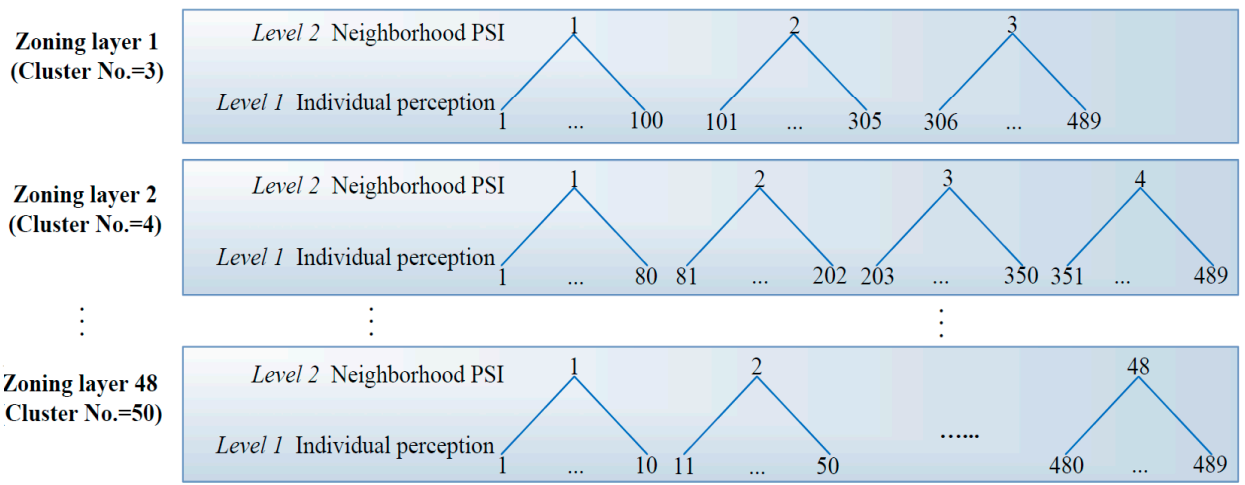

Figure 2. Workflow to produce neighborhoods in terms of Public service inequality indicators. 


\subsection{Step 1: Measuring PSI Indicators at the Census Block Level}

The first step of PSI estimation is to identify a set of accessibility-related indicators. A rights-based approach $[59,60]$ was used to identify multidimension socioeconomic indicators to estimate the PSI composite index. The renowned Ecuadorian Buen Vivir concept was proposed to create a framework of Good Living analysis in Ecuador based on human rights and nature rights [60]. In this framework, the basic needs of the human beings, such as access to good education, a proper healthcare system, and other desirable services, ensure conditions of dignity and well-being of citizens, and supports the development of capabilities that create equal opportunities for all. Therefore, based on a thorough literature review of PSI analysis [18,30,61-63], we integrated the Buen Vivir concept and selected different accessibility variables that appropriately represent the public services and which were available from statistical records.

The following seven indicators were collected to estimate neighborhood context: (1) number of households without access to drinking water (NonDri), (2) number of households without access to the sewerage system (NonSew), (3) number of households without access to the public electricity grid (NonEle), (4) number of households without access to the garbage collection service (NonCol), (5) limited access to healthcare services (Dist_H), (6) limited access to educational services (Dist_E), and (7) limited access to green areas (Green).

The information used to calculate NonDri, NonSew, NonEle, and NonCol was extracted from the 2010 Ecuadorian Population and Housing Census. The indicators Dist_H and Dist_E were calculated as the Euclidean distance to the nearest healthcare service (or educational service) from the centroid of each of the census blocks. The Green indicator was calculated as the ratio of greenspace per unit area (census block). The indicators NonDri, NonSew, NonEle, and NonCol were transformed into ratios (number of households without access to a specific public service versus the total number of households). The indicators above were chosen based on a thorough literature review $[59,60]$. The chosen indicators were applied to evaluate the social dimensions of public services inequalities, and are fundamental to understanding PSI disadvantages. After normalizing the indicators using a min-max normalization, these indicators were used as inputs for the neighborhood aggregations using six different clustering methods, as explained in Step 2.

These indicators were further used to construct a PSI composite index to represent neighborhood context at census block and the different aggregated neighborhood levels which were produced in Step 2. The PSI composite index was built by aggregating the weighted indicators. Multicollinearities in the data were evaluated based on variance inflation factors. Indicator weights were calculated by means of principal component analysis, following guidelines published by the Organization for Economic Co-operation and Development [64].

\subsection{Step 2: Classifying Census Blocks Into Hierarchical Categories of Neighborhoods Using Six Clustering Methods}

The clustering methods applied in this research were selected after a thorough literature review. All methods have been applied to define neighborhoods in previous studies. The focus of this research is by no means to exhaustively explore the various capabilities of the clustering algorithms, but rather to explore the MAUP when formulating functional neighborhoods. Therefore, we first assumed that households sharing similar quality of life characteristics will have similar access to public services. Six unsupervised clustering methods were thus separately applied to homogenize the census blocks into different groups of hierarchically aggregated neighborhood units based on seven accessibility-related indicators. These seven indicators are related to health, education, employment, and housing conditions. All indicators were proved to be correlated with health-related variables.

Six clustering methods were applied separately to aggregate the original census blocks into six hierarchies. Each hierarchy contains 47 zoning levels, whereby the cluster numbers ranged from 3 to 50. More specifically, each cluster contains the different number of census blocks based on the homogeneity characteristics of the accessibility-related dataset. Each cluster was used to identify the 
spatial pattern and geographical boundary of the respective neighborhood units. The six clustering methods used are described below:

(1) K-means clustering (Kmeans) is a simple algorithm that uses the unsupervised learning method. We used the K-means algorithm to minimize the average squared distance (absolute distance in K-means) from each data point to the cluster center [65]. The K-means is well explained by Hartigan and Wong [65].

(2) Hierarchical clustering $(H A C)$ builds a hierarchy from the bottom-up until all the data points are in a single cluster, whereby the number of clusters does not have to be defined beforehand. We thus chose the "average linkage clustering" method to find the maximum possible distance between points belonging to different clusters. This methodology has been well explained by Murtagh and Legendre [66].

(3) The self-organization maps (SOM) method, which is one of the most popular neural network models, can provide a topology preserving mapping from the high dimensional space to map units [67]. We thus used the $S O M$ to convert complex, nonlinear statistical relationships between high-dimensional original objects into simple geometric relationships on a two-dimensional display medium. This method has been fully described by Kohonen [67].

(4) Spatial "K"luster Analysis by Tree Edge Removal (SKATER) is an efficient regionalization technique that uses minimum spanning trees (MST) [68]. It transforms the regionalization problem into an optimal graph partitioning problem [35]. In this research, the seven PSI indicators represent unequal attributes to measure the dissimilarity between data points. This procedure has been fully described by Assunção et al. [35].

(5) Fuzzy clustering (Fuzzy) has the advantage over other methods that the data points possess a membership function, which ranges from 0 to 1 , to indicate the strength of membership of all the clusters. We thus used the probabilistic membership to configuration the original census blocks into a multilevel zoning group. Fuzzy clustering is well explained by Rousseeuw et al. [69].

(6) Gaussian Mixture Modelling for Model-Based Clustering (Mcluster) is useful to establish a statistical model consisting of a finite mixture of Gaussian distributions to fit the data. This algorithm offers a flexible way of inferentially learning the patterns/rules of reality from the original data points, and clusters maximize the similarity between the points. This procedure has been fully described by Fraley et al. [70].

Among these six clustering algorithms, SKATER is the connectivity model that groups census blocks over a variety of scales by using a minimum spanning tree. The SKATER-based clusters are thus spatially connected. The other five clustering algorithms are based on multivariate normal distributions of seven accessibility-related indicators, and the resulting aggregated clusters were therefore not spatially connected. Different prototypical clustering algorithms were used in this study to demonstrate the potential spatial patterns of the functional neighborhood in a hierarchical way. The resulting multiscale clusters were then used as basic neighborhood unit to further explore the spatial connectivity between neighborhood context and individual perception of place.

\subsection{Step 3: Multilevel Modeling Between Residents' Perceptions of Neighborhood and Context Information of Cluster-Defined Neighborhood}

Individualist or collective interpretations of place are useful to study contextual effects of neighborhoods [71]. Multilevel models (also known as random effects models or hierarchical linear models) have been used to evaluate neighborhood effects on individual outcomes, and can be applied to explore the best choice of area size when area-level measures are used as proxies of individual measures [56,72,73]. 


\subsubsection{Collection the Citizens' Perceptions}

Citizens' perceptions were obtained from the survey about health and quality of life carried out in the city of Quito in 2014 [63]. In this survey, a two-stage sampling approach was used to collect the data of citizens' perception. First of all, the study area was divided evenly into hexagons by using GIS tools. Eighteen hexagons were randomly chosen based on the time and financial resources available for the survey. Then, pseudo-random interviews were carried out in each sample area using a door-to-door interview petition to collect the citizens' perception data. Finally, depending on the geographical location, 489 responses to this survey including the variables perception of neighborhood safety, self-perceived health status, and perception of neighborhood cohesion and integrated with the multiscale neighborhood context to apply the multilevel modeling analysis, as explained in Section 3.3.2.

The self-perceived health status is a subjective assessment that represents individuals' integrated health perceptions [20,74]. Self-perceived neighborhood cohesion is the key aspect of neighborhood-based social capital $[75,76]$ and beyond the analogy of "capital". Self-perceived cohesion is related to trust, cooperation, and the links between individuals and human groups [77]. Neighbourhood safety is defined as the individual subjective perception of the degree of safety in the surroundings area [78,79], which includes the measurements on traffic, noise, crime rate, etc. $[80,81]$. The survey used had a response rate of $61 \%$ and a sampling error of \pm 4 [63].

\subsubsection{Multilevel Modeling}

As we are explicitly interested in variation within and between neighborhoods, the random intercepts and slopes were specified to covary in the multilevel modeling [73]. The individual-level citizens' perceptions were treated as dependent variables, and the PSI contextual value of each neighborhood unit was treated as the independent variable. The multilevel model was carried out by using the lme4 library in R. It is expressed by the formula [82]:

$$
Y_{i j}=\beta_{0}+\beta_{10} P S I_{i j}+u_{0 j}+u_{1 j} P S I_{i j}+e_{i j}
$$

where $Y_{i j}$ is the perception (self-perceived health status/neighborhood cohesion/neighborhood safety) of individual $i$ in cluster $j, P S I_{i j}$ is the PSI index representing the contextual information of cluster $j, \beta_{0}$ is the overall mean across the whole clustering layers, $u_{0 j}, u_{1 j}$ represents the effects of cluster $j$ on $Y_{i j}$, and $e_{i j}$ is an individual-level residual.

The variance partition coefficient (VPC) and the log-likelihood value (LR) were used to explore the multiscale variances of the neighborhood PSI contextual characteristics in relation to citizens' perception of place. The VPC can be expressed as:

$$
V P C=\frac{\delta_{\mu}^{2}}{\delta_{e}^{2}+\delta_{\mu}^{2}}
$$

where $\delta_{u}^{2}$ is the external variance between groups and $\delta_{e}^{2}$ is the internal variance within groups. The VPC measures the percentage of the variance in $Y_{i j}$ that can be attributed to differences between clusters. The higher the VPC, the higher the external variance of $Y_{i j}$ and the lower the internal variances of $Y_{i j}$, which means more homogeneity of citizens' perceptions within a neighborhood.

The LR statistic was used to test the significance of the effects of the cluster or neighborhoods on $Y_{i j}$. If LR is larger than 3.84, it means that there are significant neighborhood effects on citizens' perceptions. The LR statistic is calculated as follows:

$$
L R=-2 \log L_{1}-\left(-2 \log L_{2}\right)
$$


where $L_{1}$ is the likelihood value of the multilevel model, and $L_{2}$ is the likelihood value of a null single-level model.

\section{Results}

In the case of census blocks, the LR values for perceptions of neighborhood social cohesion, self-perceived health status, and perceptions of neighborhood safety were $0.608,0.865$, and 0.245 respectively; all values were lower than the threshold of 3.83. These results suggest that there are not significant internal similarities of individual perceptions of place in the corresponding census blocks. Moreover, the census blocks could not significantly represent the external variability of the PSI values in relation to self-perceived health status, perceptions of neighborhood safety, or perceptions of neighborhood social cohesion.

As shown in Figure 3, when we used the perceptions of neighborhood safety to validate the PSI contextual values, 35 to $80 \%$ of clustering layers in each clustering algorithm could effectively explain the internal variability of perceptions of neighborhood safety. In the case of models using the self-perceived health status, excepting the $H A C$ clustering algorithm $(96 \%$ of clustering layers with LR larger than 3.84), the proportion of clustering layers that can explain the internal variability of self-perceived health status dramatically declined from 8 to $26 \%$. Additionally, there are practically no clustering layers in all the six clustering algorithms that can effectively demonstrate the internal variability of perceptions of neighborhood social cohesion. In conclusion, the neighborhood context in relation to the PSI index influences the variances of self-perceived health status and perceptions of neighborhood safety, but not variances of perceptions of neighborhood social cohesion.

Table 1 shows the averages of the VPCs with an LR higher than 3.84. The higher the VPC, the lower the internal (neighborhood) heterogeneities and the higher the external heterogeneities. In the case of the perceptions of neighborhood safety and self-perceived health status, results show that neighborhoods constructed using the different cluster algorithms are places where citizens share similar perceptions (VPCs averages higher than 0.50). Especially in the case of self-perceived health status, citizens living in different kinds of neighborhoods share practically equivalent perceptions (VPCs closer or equal to 1). By contrast, in the case of the perceptions of neighborhood social cohesion, only the neighborhoods created with the SKATER algorithm are places where people share similar perceptions of social cohesion. In general, the SKATER-based neighborhood units which account for the spatial connectivity features demonstrate higher spatial efficacy than the other five clustering results in terms of connecting objective neighborhood context information and subjective individual perceptions of place.

Table 1. The average variance partition coefficients (VPCs) of the multilevel models in relation to the citizens' perceptions and the neighborhood PSI context based on six clustering algorithms. (Fuzzy = Fuzzy clustering, HAC = Hierarchical clustering, Kmeans = K-means clustering, Mcluster $=$ Gaussian Mixture Modelling for Model-Based Clustering, SKATER = Spatial "K"luster Analysis by Tree Edge Removal, SOM = Self-organization maps).

\begin{tabular}{cccccccc}
\hline & & Fuzzy & HAC & Kmeans & Mcluster & SKATER & SOM \\
\hline \multirow{2}{*}{$\begin{array}{c}\text { Neighborhood } \\
\text { safety }\end{array}$} & Avg VPCs (LR > 3.84) & 0.815 & 1 & 0.773 & 0.572 & 0.530 & 0.732 \\
\cline { 2 - 8 } & Variance $(\mathrm{LR}>3.84)$ & 0.340 & 0.446 & 0.366 & 0.270 & 0.322 & 0.260 \\
\hline \multirow{2}{*}{$\begin{array}{c}\text { Neighborhood } \\
\text { social cohesion }\end{array}$} & Avg VPCs $(\mathrm{LR}>3.84)$ & 0 & 0 & 0.078 & 0.060 & 0.65 & 0 \\
\cline { 2 - 8 } & Variance $(\mathrm{LR}>3.84)$ & 0 & 0 & 0 & 0 & 0.303 & 0 \\
\hline \multirow{2}{*}{\begin{tabular}{c} 
Health status \\
\cline { 2 - 8 }
\end{tabular}} & Avg VPCs $(\mathrm{LR}>3.84)$ & 0.948 & 1 & 0.985 & 0.985 & 0.916 & 0.991 \\
\cline { 2 - 8 } & Variance $(\mathrm{LR}>3.84)$ & 0.249 & 0.143 & 0.433 & 0.433 & 0.398 & 0.272 \\
\hline
\end{tabular}



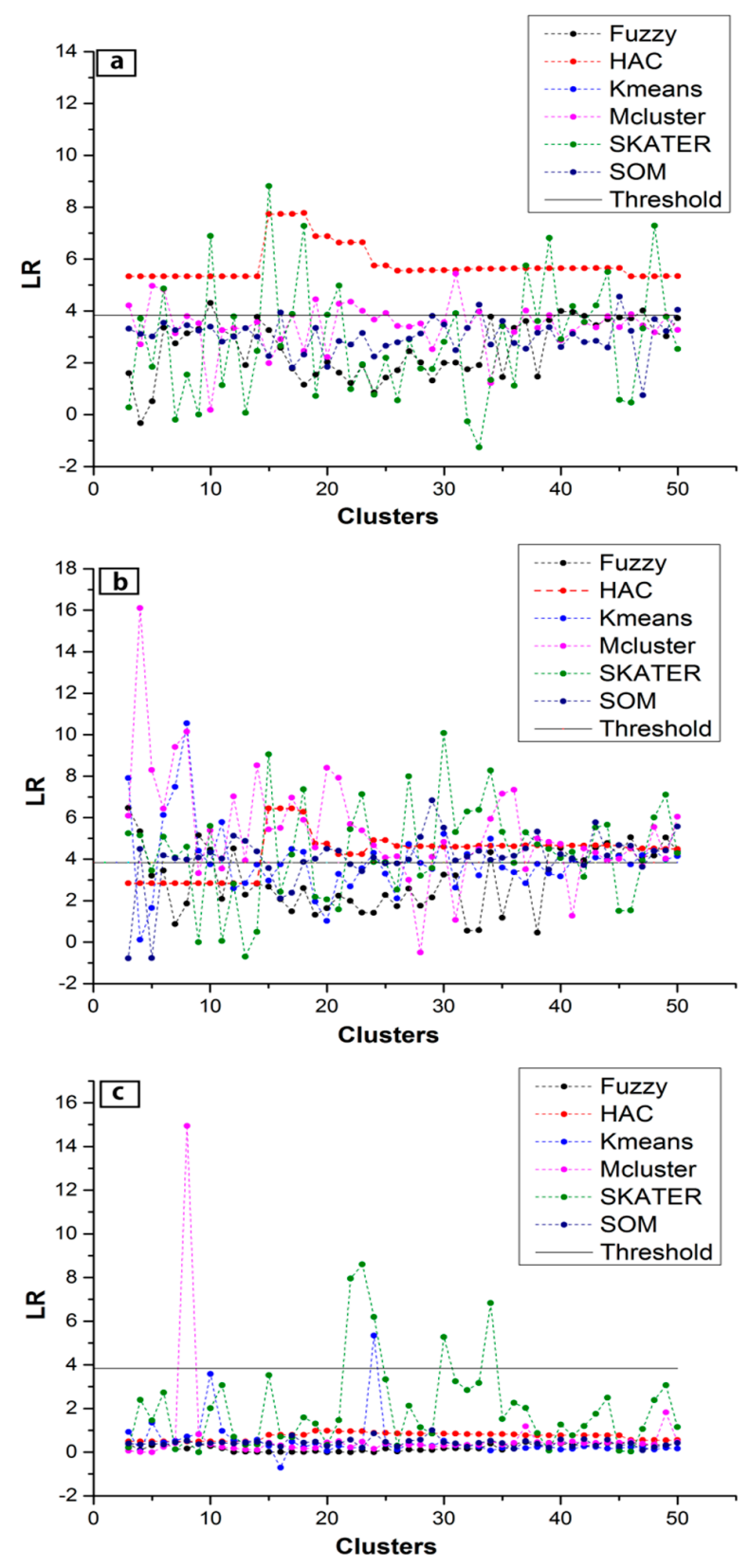

Figure 3. The log-likelihood statistic of the multilevel models regarding PSI contextual values and citizens' perceptions of: (a) the self-perceived health status; (b) perceptions of neighborhood safety; (c) perceptions of neighborhood social cohesion.

In conclusion, all six clustering methods are successful in generating alternative neighborhoods that represent PSI and influence perceptions of neighborhood safety and self-perceived health status. The VPCs reported above also suggest that citizens' perceptions are tied to "socially meaningful" neighborhoods, for instance, neighborhoods in relation to PSI. Our results also support the claim that the socio-physical elements of the environment can reinforce the relationships between citizens' attitudes and their physical space, as well as the relationships between citizens and their sense of place.

\section{Discussion}

In this research, we (1) aggregated census blocks to generate meaningful neighborhood (cluster) units in relation to public services inequality using six clustering algorithms, and (2) examined the 
internal neighborhood differences of citizens' perceptions related to health status, neighborhood safety, and neighborhood social cohesion.

Regarding the question of whether the internal variability of individual perceptions can be explained by the neighborhood context, our results suggest that this is strongly influenced by the zoning scale. Furthermore, there is no decisive way to identify the meaningful neighborhoods that are consistent representations of place in relation to citizens' perceptions. Our findings show that different types of clustering methods allow us to aggregate the neighborhood units that effectively reflect the internal heterogeneities of citizens' perceptions. Therefore, it is worthwhile to test the efficiency and sensitivity of these clustering algorithms in a hierarchical way when they are selected for the neighborhood analysis.

Previous studies $[83,84]$ have showed that if clustering algorithms generate highly similar partitions, it is a good indicator that the actual structure of the dataset has been discovered. In this study, although six different clustering algorithms have served to explore new spatial delineations of neighborhoods in a hierarchical way, our findings also imply that the seven census-based accessibility indicators selected to represent PSI are reasonable for interpreting and understanding public services inequalities in Quito. Particularly, these indicators are related to the fundamental human rights that a population should have: access to clean water, electricity, education, healthcare, environmental protection, and so on $[20,85]$. They can be linked to the measure of social deprivation and health-related social dimensions $[20,60]$, as well as to enhance the understanding of a variety of place interpretations $[86,87]$. The applied methods on indicators collection and processing are available and transferable to other cities since they are conceptually similar [61].

We should note that there is not one ideal dataset to represent socially meaningful neighborhoods. The combinations of different social indicators may lead to different alternative neighborhoods and different relations of these neighborhoods with citizens' perceptions. Therefore, it is crucial to integrate different socioeconomic variables to study neighborhoods and social perceptions of place in the future. The framework presented in this study converts the static statistical data into a graphic diagram in a transferable and feasible way. Therefore, different kinds of composite indicators based on multiple dimensions of socioeconomic-environmental features should be further applied to examine the uncertainty and sensitivity of indicators in neighborhood identifications.

Our results also suggest that neighborhood contexts do not strongly influence variances in perceptions of neighborhood social cohesion. Thus, it can be said that, in this study area, the perceptions of neighborhood social cohesion are deeply dependent on social cooperation and the conditions of other neighborhoods. However, within each neighborhood, there are marked differences in perceptions of neighborhood social cohesion between citizens. This statement is consistent with the idea that social cohesion is an indicator of inequality at the individual level, but not at the neighborhood level $[88,89]$.

Unlike the case of perceptions of neighborhood social cohesion, external heterogeneities of neighborhood contexts strongly influence internal variances of self-perceived health status and perceptions of neighborhood safety. This result also suggests that limitations of public services accessibility in a neighborhood have a similar impact on perceptions of the health and neighborhood safety of the residents living in the neighborhood. Therefore, data obtained from the census and surveys support individualist or collective interpretations of neighborhood identification [7,72].

However, individual perceptions cannot fully reflect all the individuals' experiences in differential types of places or neighborhoods. This limitation is related to the "atomistic fallacy" [16]. The obtained results of the multilevel models show that the atomistic fallacy may decrease when the associations between variables at the neighborhood level and the perception at the individual level are explored. Nevertheless, some neighborhood-level PSI values were to some extent biased in relation to the citizens' perceptions. The uncertainty of individual perceptions of place identification needs to be addressed and further discussed in future research.

This study is an example of aggregating census blocks in neighborhoods with homogenous PSI index values. The study also contributes to the understanding of how inequalities in neighborhoods 
impact perceptions of health, neighborhood cohesion, and neighborhood safety. Our findings show that it does matter how the neighborhoods' boundaries are delineated (scale of aggregation), and they reveal how mapping functional neighborhoods is heavily dependent on social indicators (e.g., the indicators used to construct the PSI index) and the perceptions of citizens. At the same time, spatial connectivity is an essential factor in determining the significance of neighborhood identification, because human activities related to place perception may demonstrate higher similarity in the form of neighborhoods with spatial extent rather than isolated sites. Therefore, different types of functional connectivity analyses, such as the modified SOM algorithm [90], spatial non-stationarity model [91], or spatial autoregressive model [92], should be implemented to extend the applications of clustering methods in urban segregation analysis.

\section{Conclusions}

This research combines two ways to assess urban segregations: objectively, via neighborhood contexts aggregation from census data sources, and subjectively, according to perceptions that can be considered individuals' identifications with their neighborhoods. Different hierarchical groups of neighborhoods based on six types of clustering algorithms have illustrated how well these two ways of urban segregation measurement agree with each other. In particular, the multilevel modeling applied in this study deals with the spatial mis-match issue between objective PSI estimates and subjective citizens' perceptions across multiple neighborhood scales.

Unravelling the internal variability of the individual perceptions explained by a neighborhood context across multiscale neighborhoods allowed a better understanding and interpretation of public services inequality in Quito, Ecuador. Our methodology tackles the well-recognized difficulty of functional neighborhood delineation, both at the objective and the subjective levels. At the same time, we also realize that there is no decisive way to define the most suitable neighborhood scale in public services inequality analysis. The proposed multilevel modeling analysis enables planners to explain the internal/external heterogeneities of individual perceptions within each neighborhood unit, yet these variabilities can only offer suggestions but not the solutions of MAUP effect in different kinds of neighborhoods obtained.

This research is a first step to explore the multiscale relationships between objective and subjective indicators with regard to combinations of public services. The workflow proposed in this study plays a crucial role in propagating mixed-methods approaches (qualitative-quantitative). Our results can support decision-makers in developing and applying specific policies regarding health and social equity across multiple scales. Because cities are complex urban systems that encompass phenomena that work across different scales, the explanations of different functional neighborhoods and their spatial consistencies with the subjective individual perceptions of place require differentiated qualitative and quantitative approaches, such as the models applied in the present study.

Acknowledgments: The authors gratefully acknowledge the Ecuador's Ministry of Environment for providing land use and land cover information. We would also like to thank to the Ecuador's Ministry of Health and the Ecuador's Ministry of Education for providing the geo-referenced health and educational services data for the city of Quito.

Author Contributions: Chunzhu Wei carried out the substantial contributions to the conception and design of the study, participated in the analysis and drafted the manuscript. Pablo Cabrera Barona participated in the design of the study, performed the data collection, part of the statistical analysis and drafted part of the manuscript. Thomas Blaschke participated in the design of the study and helped to draft the manuscript. All authors read and approved the final manuscript.

Conflicts of Interest: The authors declare no conflicts of interest.

Funding: The field survey used in this study was funded by the Government of Ecuador through the Ecuadorian Secretary of Higher Education, Science, Technology and Innovation and the Ecuadorian Institute of Promotion of Human Talent (Scholarship contract No. 375-2012). It has also partially been funded by the China Scholarship Council (contract No. CSC 201306070014), and the Austrian Science Fund (FWF) through the Doctoral College GIScience (DK W 1237-N23). 


\section{References}

1. Huie, S.A.B. The Concept of Neighborhood in Health and Mortality Research. Soc. Spectr. 2001, 21, 341-358. [CrossRef]

2. Haynes, R.; Daras, K.; Reading, R.; Jones, A. Modifiable neighbourhood units, zone design and residents' perceptions. Health Place 2007, 13, 812-825. [CrossRef] [PubMed]

3. Subramanian, S.V.; Lochner, K.A.; Kawachi, I. Neighborhood differences in social capital: A compositional artifact or a contextual construct? Health Place 2003, 9, 33-44. [CrossRef]

4. Dunford, M. Capital accumulation and regional development in France. Geoforum 1979, 10, 81-108. [CrossRef]

5. Bógus, L.M.M. Urban segregation: A theoretical approach. In Proceedings of the 13th Biennial Conference of International Planning History Society, IPHS, Chicago, IL, USA, 10-13 July 2008.

6. Weeks, J.R. Population, An Introduction to Concepts and Issues; Cram101 Textbook Reviews; Wadsworth Publishing Company: Belmont, CA, USA, 2016; ISBN 978-1-4970-5055-6.

7. Kawachi, I.; Berkman, L.F. Neighborhoods and Health; Oxford University Press: Oxford, UK, 2003; ISBN 978-0-19-974792-4.

8. Guo, J.Y.; Bhat, C.R. Operationalizing the concept of neighborhood: Application to residential location choice analysis. J. Transp. Geogr. 2007, 15, 31-45. [CrossRef]

9. Schuurman, N.; Bell, N.; Dunn, J.R.; Oliver, L. Deprivation indices, population health and geography: An evaluation of the spatial effectiveness of indices at multiple scales. J. Urban Health 2007, 84, 591-603. [CrossRef] [PubMed]

10. LeClere, F.B.; Rogers, R.G.; Peters, K.D. Ethnicity and Mortality in the United States: Individual and Community Correlates. Soc. Forces 1997, 76, 169-198. [CrossRef]

11. Diez-Roux, A.V.; Nieto, F.J.; Muntaner, C.; Tyroler, H.A.; Comstock, G.W.; Shahar, E.; Cooper, L.S.; Watson, R.L.; Szklo, M. Neighborhood Environments and Coronary Heart Disease: A Multilevel Analysis. Am. J. Epidemiol. 1997, 146, 48-63. [CrossRef] [PubMed]

12. Stafford, M.; Duke-Williams, O.; Shelton, N. Small area inequalities in health: Are we underestimating them? Soc. Sci. Med. 2008, 67, 891-899. [CrossRef] [PubMed]

13. Lin, N. Inequality in Social Capital. Contemp. Soc. 2000, 29, 785-795. [CrossRef]

14. World Health Organization (WHO). Environment and Health Risks: A Review of the Influence and Effects of Social Inequalities; WHO: Geneva, Switzerland, 2010.

15. Pearl, M.; Braveman, P.; Abrams, B. The relationship of neighborhood socioeconomic characteristics to birthweight among 5 ethnic groups in California. Am. J. Public Health 2001, 91, 1808-1814. [CrossRef] [PubMed]

16. Macintyre, S.; Ellaway, A.; Cummins, S. Place effects on health: How can we conceptualise, operationalise and measure them? Soc. Sci. Med. 2002, 55, 125-139. [CrossRef]

17. Lotfi, S.; Koohsari, M.J. Measuring objective accessibility to neighborhood facilities in the city (A case study: Zone 6 in Tehran, Iran). Cities 2009, 26, 133-140. [CrossRef]

18. Apparicio, P.; Abdelmajid, M.; Riva, M.; Shearmur, R. Comparing alternative approaches to measuring the geographical accessibility of urban health services: Distance types and aggregation-error issues. Int. J. Health Geogr. 2008, 7, 7. [CrossRef] [PubMed]

19. De la Fuente, H.; Rojas, C.; Salado, M.J.; Carrasco, J.A.; Neutens, T. Socio-Spatial Inequality in Education Facilities in the Concepción Metropolitan Area (Chile). Curr. Urban Stud. 2013, 1, 117-129. [CrossRef]

20. Wei, C.; Cabrera-Barona, P.; Blaschke, T. Local Geographic Variation of Public Services Inequality: Does the Neighborhood Scale Matter? Int. J. Environ. Res. Public. Health 2016, 13. [CrossRef] [PubMed]

21. Lopez, R.P.; Hynes, H.P. Obesity, physical activity, and the urban environment: Public health research needs. Environ. Health 2006, 5, 25. [CrossRef] [PubMed]

22. Centers for Disease Control and Prevention (CDC). Neighborhood safety and the prevalence of physical inactivity-Selected states, 1996. MMWR Morb. Mortal. Wkly. Rep. 1999, 48, 143-146.

23. Zenk, S.N.; Schulz, A.J.; Israel, B.A.; James, S.A.; Bao, S.; Wilson, M.L. Neighborhood Racial Composition, Neighborhood Poverty, and the Spatial Accessibility of Supermarkets in Metropolitan Detroit. Am. J. Public Health 2005, 95, 660-667. [CrossRef] [PubMed] 
24. Dietz, R.D. The estimation of neighborhood effects in the social sciences: An interdisciplinary approach. Soc. Sci. Res. 2002, 31, 539-575. [CrossRef]

25. White, A.N. Accessibility and Public Facility Location. Econ. Geogr. 1979, 55, 18-35. [CrossRef]

26. Gao, Y.; Gao, J.; Chen, J.; Xu, Y.; Zhao, J. Regionalizing aquatic ecosystems based on the river subbasin taxonomy concept and spatial clustering techniques. Int. J. Environ. Res. Public Health 2011, 8, 4367-4385. [CrossRef] [PubMed]

27. Hosking, J.R.M.; Wallis, J.R. Some statistics useful in regional frequency analysis. Water Resour. Res. 1993, 29, 271-281. [CrossRef]

28. Breiger, R.L.; Boorman, S.A.; Arabie, P. An algorithm for clustering relational data with applications to social network analysis and comparison with multidimensional scaling. J. Math. Psychol. 1975, 12, 328-383. [CrossRef]

29. Caspi, A.; Taylor, A.; Moffitt, T.E.; Plomin, R. Neighborhood Deprivation Affects Children's Mental Health: Environmental Risks Identified in a Genetic Design. Psychol. Sci. 2000, 11, 338-342. [CrossRef] [PubMed]

30. Lalloué, B.; Monnez, J.M.; Padilla, C.; Kihal, W.; Meur, N.; Zmirou-Navier, D. A statistical procedure to create a neighborhood socioeconomic index for health inequalities analysis. Int. J. Equity Health 2013, 12. [CrossRef] [PubMed]

31. Andrews, F.M.; Withey, S.B. Social Indicators of Well-Being: Americans' Perceptions of Life Quality; Springer: New York, NY, USA, 2012; ISBN 978-1-4684-2253-5.

32. Marques, E.C.L. Opportunities and Deprivation in the Urban South: Poverty, Segregation and Social Networks in São Paulo; Routledge: London, UK, 2016; ISBN 978-1-317-08533-1.

33. Openshaw, S.; Rao, L. Algorithms for Reengineering 1991 Census Geography. Environ. Plan. A 1995, 27, 425-446. [CrossRef] [PubMed]

34. Cockings, S.; Martin, D. Zone design for environment and health studies using pre-aggregated data. Soc. Sci. Med. 2005, 60, 2729-2742. [CrossRef] [PubMed]

35. AssunÇão, R.M.; Neves, M.C.; Câmara, G.; Freitas, C.D.C. Efficient regionalization techniques for socio-economic geographical units using minimum spanning trees. Int. J. Geogr. Inf. Sci. 2006, 20, 797-811. [CrossRef]

36. Menezes, V.S.A.; da Silva, R.T.; de Souza, M.F.; Oliveira, J.; de Mello, C.E.R.; de Souza, J.M.; Zimbrão, G. Mining and Analyzing Organizational Social Networks Using Minimum Spanning Tree. In On the Move to Meaningful Internet Systems: OTM 2008 Workshops; Meersman, R., Tari, Z., Herrero, P., Eds.; Springer: Berlin/Heidelberg, Germany, 2008; pp. 18-19. ISBN 978-3-540-88874-1.

37. Banerjee, S.; Badr, Y.; Al-Shammari, E.T. Analyzing Tweet Cluster Using Standard Fuzzy C Means Clustering. In Social Networks: A Framework of Computational Intelligence; Pedrycz, W., Chen, S.-M., Eds.; Springer: Cham, Switzerland, 2014; ISBN 978-3-319-02992-4.

38. Parenteau, M.-P.; Sawada, M.C. The modifiable areal unit problem (MAUP) in the relationship between exposure to NO2 and respiratory health. Int. J. Health Geogr. 2011, 10, 58. [CrossRef] [PubMed]

39. Kronthaler, F. Economic capability of East German regions: Results of a cluster analysis. Reg. Stud. 2005, 39, 739-750. [CrossRef]

40. Openshaw, S. A Geographical Solution to Scale and Aggregation Problems in Region-Building, Partitioning and Spatial Modelling. Trans. Inst. Br. Geogr. 1977, 2, 459-472. [CrossRef]

41. Alvanides, S.; Openshaw, S. Zone Design for Planning and Policy Analysis. In Geographical Information and Planning; Stillwell, D.J., Geertman, P.S., Openshaw, D.S., Eds.; Springer: Berlin/Heidelberg, Germany, 1999; pp. 299-315. ISBN 978-3-642-08517-8.

42. Wooldredge, J. Examining the (ir)relevance of Aggregation Bias for Multilevel Studies of Neighborhoods and Crime with an Example Comparing Census Tracts to Official Neighborhoods in Cincinnati. Criminology 2002, 40, 681-710. [CrossRef]

43. Stylidis, D. Place Attachment, Perception of Place and Residents' Support for Tourism Development. Tour. Plan. Dev. 2017. [CrossRef]

44. Basso, K.H. Wisdom Sits in Places: Landscape and Language among the Western Apache; UNM Press: Albuquerque, NM, USA, 1996; ISBN 978-0-8263-2705-5.

45. Kudryavtsev, A.; Stedman, R.C.; Krasny, M.E. Sense of place in environmental education. Environ. Educ. Res. 2012, 18, 229-250. [CrossRef] 
46. Adams, P.C.; Gynnild, A. Environmental Messages in Online Media: The Role of Place. Environ. Commun. 2013, 7, 113-130. [CrossRef]

47. Madanipour, A. Why are the Design and Development of Public Spaces Significant for Cities? Environ. Plan. B Plan. Urban Anal. City Sci. 1999, 26, 879-891. [CrossRef]

48. Melvin, P.M. Changing Contexts: Neighborhood Definition and Urban Organization. Am. Q. 1985, 37, 357-367. [CrossRef]

49. Ruddick, S. Constructing difference in public spaces: Race, class, and gender as interlocking systems. Urban Geogr. 1996, 17, 132-151. [CrossRef]

50. Cook, T.; Irwin, M. Aggregation Issues in Neighborhood Research: A Comparison of Several Levels of Census Geography and Resident Defined Neighborhoods; Association for Public Policy and Management: Atlanta, GA, USA, 2004.

51. Hewko, J.; Smoyer-Tomic, K.E.; Hodgson, M.J. Measuring Neighbourhood Spatial Accessibility to Urban Amenities: Does Aggregation Error Matter? Environ. Plan. A 2002, 34, 1185-1206. [CrossRef]

52. Wandersman, A.; Florin, P. Citizen Participation and Community Organizations. In Handbook of Community Psychology; Rappaport, J., Seidman, E., Eds.; Kluwer Academic Publishers: Dordrecht, The Netherlands, 2000; pp. 247-272. ISBN 978-1-4613-6881-6.

53. Marschall, M.J. Citizen Participation and the Neighborhood Context: A New Look at the Coproduction of Local Public Goods. Polit. Res. Q. 2004, 57, 231-244. [CrossRef]

54. Rende, S.; Donduran, M. Neighborhoods in Development: Human Development Index and Self-organizing Maps. Soc. Indic. Res. 2011, 110, 721-734. [CrossRef]

55. Sun, I.Y.; Payne, B.K.; Wu, Y. The impact of situational factors, officer characteristics, and neighborhood context on police behavior: A multilevel analysis. J. Crim. Justice 2008, 36, 22-32. [CrossRef]

56. Duncan, C.; Jones, K.; Moon, G. Context, composition and heterogeneity: Using multilevel models in health research. Soc. Sci. Med. 1998, 46, 97-117. [CrossRef]

57. Scarbrough, E.; Tanenbaum, E. Research Strategies in the Social Sciences: A Guide to New Approaches; OUP Oxford: Oxford, UK, 1998; ISBN 978-0-19-829238-8.

58. Hoffman, K.; Centeno, M.A. The Lopsided Continent: Inequality in Latin America. Annu. Rev. Soc. 2003, 29, 363-390. [CrossRef]

59. Mideros, A. Ecuador: Defining and measuring multidimensional poverty, 2006-2010. Cepal Rev. 2012, 108, 50-67.

60. Cabrera-Barona, P.; Wei, C.; Hagenlocher, M. Multiscale evaluation of an urban deprivation index: Implications for quality of life and healthcare accessibility planning. Appl. Geogr. 2016, 70, 1-10. [CrossRef]

61. Schkolnik, S.; Chackiel, J. América Latina: Aspectos Conceptuales de Los Censos del 2000; Serie Manuales; Naciones Unidas: Santiago, Chile, 1999.

62. Flacke, J.; Schüle, S.A.; Köckler, H.; Bolte, G. Mapping Environmental Inequalities Relevant for Health for Informing Urban Planning Interventions-A Case Study in the City of Dortmund, Germany. Int. J. Environ. Res. Public Health 2016, 13, 711. [CrossRef] [PubMed]

63. Cabrera-Barona, P.; Blaschke, T.; Kienberger, S. Explaining Accessibility and Satisfaction Related to Healthcare: A Mixed-Methods Approach. Soc. Indic. Res. 2016. [CrossRef]

64. OECD; European Commission. Handbook on Constructing Composite Indicators: Methodology and User Guide; OECD: Paris, France, 2008; ISBN 978-92-64-04346-6.

65. Hartigan, J.A.; Wong, M.A. Algorithm AS 136: A K-Means Clustering Algorithm. J. R. Stat. Soc. Ser. C Appl. Stat. 1979, 28, 100-108. [CrossRef]

66. Murtagh, F.; Legendre, P. Ward's Hierarchical Agglomerative Clustering Method: Which Algorithms Implement Ward's Criterion? J. Classif. 2014, 31, 274-295. [CrossRef]

67. Kohonen, T. The self-organizing map. Proc. IEEE 1990, 78, 1464-1480. [CrossRef]

68. Aho, A.V.; Hopcroft, J.E.; Ullman, J. Data Structures and Algorithms, 1st ed.; Addison-Wesley Longman Publishing Co. Inc.: Boston, MA, USA, 1983; ISBN 978-0-201-00023-8.

69. Rousseeuw, P.J.; Kaufman, L.; Trauwaert, E. Fuzzy clustering using scatter matrices. Comput. Stat. Data Anal. 1996, 23, 135-151. [CrossRef]

70. Fraley, C.; Raftery, A.E. How Many Clusters? Which Clustering Method? Answers via Model-Based Cluster Analysis. Comput. J. 1998, 41, 578-588. [CrossRef] 
71. Poortinga, W. Social capital: An individual or collective resource for health? Soc. Sci. Med. 2006, 62, $292-302$. [CrossRef] [PubMed]

72. Diez Roux, A.V. The study of group-level factors in epidemiology: Rethinking variables, study designs, and analytical approaches. Epidemiol. Rev. 2004, 26, 104-111. [CrossRef] [PubMed]

73. O'Campo, P. Invited commentary: Advancing theory and methods for multilevel models of residential neighborhoods and health. Am. J. Epidemiol. 2003, 157, 9-13. [CrossRef] [PubMed]

74. Miilunpalo, S.; Vuori, I.; Oja, P.; Pasanen, M.; Urponen, H. Self-rated health status as a health measure: The predictive value of self-reported health status on the use of physician services and on mortality in the working-age population. J. Clin. Epidemiol. 1997, 50, 517-528. [CrossRef]

75. Baum, F. The New Public Health; Oxford University Press: Oxford, UK, 2003; pp. 1-607.

76. Gebel, K.; Bauman, A.E.; Petticrew, M. The physical environment and physical activity: A critical appraisal of review articles. Am. J. Prev. Med. 2007, 32, 361-369. [CrossRef] [PubMed]

77. McCracken, M. Social cohesion and macroeconomic performance. In Proceedings of the CSLS Conference on the State of Living Standards and the Quality of Life in Canada, Ottawa, ON, Canada, 30-31 October 1998.

78. Bennett, G.G.; McNeill, L.H.; Wolin, K.Y.; Duncan, D.T.; Puleo, E.; Emmons, K.M. Safe To Walk? Neighborhood Safety and Physical Activity among Public Housing Residents. PLoS Med. 2007, 4, e306. [CrossRef] [PubMed]

79. Humpel, N.; Owen, N.; Leslie, E. Environmental factors associated with adults' participation in physical activity: A review. Am. J. Prev. Med. 2002, 22, 188-199. [CrossRef]

80. Sun, V.K.; Stijacic Cenzer, I.; Kao, H.; Ahalt, C.; Williams, B.A. How Safe is Your Neighborhood? Perceived Neighborhood Safety and Functional Decline in Older Adults. J. Gen. Intern. Med. 2012, 27, 541-547. [CrossRef] [PubMed]

81. Lewis, D.A.; Maxfield, M.G. Fear in the Neighborhoods: An Investigation of the Impact of Crime. J. Res. Crime Delinquency 1980, 17, 160-189. [CrossRef]

82. Kreft, I.G.; Kreft, I.; de Leeuw, J. Introducing Multilevel Modeling; Sage: London, UK, 1998; ISBN 0-7619-5141-5.

83. Handl, J.; Knowles, J.; Kell, D.B. Computational cluster validation in post-genomic data analysis. Bioinformatics 2005, 21, 3201-3212. [CrossRef] [PubMed]

84. Cormode, G.; McGregor, A. Approximation Algorithms for Clustering Uncertain Data. In Proceedings of the Twenty-Seventh ACM SIGMOD-SIGACT-SIGART Symposium on Principles of Database Systems PODS'08; ACM: New York, NY, USA, 2008; pp. 191-200.

85. Cabrera-Barona, P.; Blaschke, T.; Gaona, G. Deprivation, Healthcare Accessibility and Satisfaction: Geographical Context and Scale Implications. Appl. Spat. Anal. Policy 2017. [CrossRef]

86. Ngom, R.; Gosselin, P.; Blais, C. Reduction of disparities in access to green spaces: Their geographic insertion and recreational functions matter. Appl. Geogr. 2016, 66, 35-51. [CrossRef]

87. Adlakha, D.; Hipp, J.A.; Brownson, R.C. Adaptation and Evaluation of the Neighborhood Environment Walkability Scale in India (NEWS-India). Int. J. Environ. Res. Public Health 2016, 13, 401. [CrossRef] [PubMed]

88. Bauman, A.; Smith, B.; Stoker, L.; Bellew, B.; Booth, M. Geographical influences upon physical activity participation: Evidence of a "coastal effect". Aust. N. Z. J. Public Health 1999, 23, 322-324. [CrossRef] [PubMed]

89. Baum, F.E.; Ziersch, A.M.; Zhang, G.; Osborne, K. Do perceived neighbourhood cohesion and safety contribute to neighbourhood differences in health? Health Place 2009, 15, 925-934. [CrossRef] [PubMed]

90. Craddock, R.C.; James, G.A.; Holtzheimer, P.E.; Hu, X.P.; Mayberg, H.S. A whole brain fMRI atlas generated via spatially constrained spectral clustering. Hum. Brain Mapp. 2012, 33, 1914-1928. [CrossRef] [PubMed]

91. Gaetan, C.; Guyon, X. Statistics for spatial models. In Spatial Statistics and Modeling; Springer: New York, NY, USA, 2010; pp. 149-248. ISBN 978-0-387-92256-0.

92. Anselin, L. Spatial Econometrics: Methods and Models; Springer: Amsterdam, The Netherlands, 2013; ISBN 978-94-015-7799-1. 